\title{
Smart Wearable Visualizing System for People with Hearing Impairment
}

\section{K. Hema, Velmurugan S, Mohanraj S, Dhilipkumar T}

\begin{abstract}
In worldwide around 466 million people have struggling because of hearing impairment and 34 million of those are children. Hearing loss may cause due to aging and exploring of louder sounds, complications at birth, certain contagious diseases, prolonged ear infections. Nowadays people with hearing disability uses hearing aids, but due to the environment noise interference it won't be efficient and also they don't separate speech and noise in noisy environments. In order to intimate the deaf person, we have introduced a system which includes several means of visualizing both ambient and speech sounds and presents a combination of visualization displays incorporated into one system that would help the hearing impaired people to an enhanced awareness of their surroundings.
\end{abstract}

Keywords: Hearing loss, Visualizing ambient and speech sounds, awareness of surroundings.

\section{INTRODUCTION}

As per the assessment one in three people over the age of 65 years and number of 466 million individuals worldwide are struggling with hearing impairment.

It causes a problem at any point in the hearing trail and depending on which type of loss.

There are two categories:

- Conductive hearing loss

- $\quad$ Sensory Neural hearing loss

Conductive hearing loss happens due to the defects in the part of outer and middle ear for example ear canal, eardrum and middle ear bones. It causes the problems like earwax, fluid or infections in middle ear, small holes in ear drum. People with a conductive hearing loss can be corrected medically or surgically. Another is sensory neural hearing loss happens due to the defects in the part of inner ear for example cochlea, nerve, vestibular organs. The one we discussed now is the most common type of hearing loss and is caused damage to tiny cell in inner ear; thereby it could not communicate the signal to brain. The wearable device will acts as assistive device for the hearing impaired. It will potentially modify the lives of millions of hearing impaired people. These kind of smart device aims to assist hearing impaired people to lead a comfortable life. It does this in two different methods.

Revised Manuscript Received on February 28, 2020.

* Correspondence Author

L.K. Hema*, Professor \& HoD, Dept. of ECE, Aarupadai Veedu Institute Of Technology, VMRF, Paiyanoor. Chennai, India.

Velmurugan S,UG student, Dept. of ECE, Aarupadai Veedu Institute Of Technology, VMRF, Paiyanoor. Chennai, India.

Mohanraj S, UG student, Dept. of ECE, Aarupadai Veedu Institute Of Technology, VMRF, Paiyanoor. Chennai, India.

Dhilip kumar T, UG student, Dept. of ECE, Aarupadai Veedu Institute Of Technology, VMRF, Paiyanoor. Chennai, India.

(C) The Authors. Published by Blue Eyes Intelligence Engineering and Sciences Publication (BEIESP). This is an open access article under the CC-BY-NC-ND license http://creativecommons.org/licenses/by-nc-nd/4.0/
One is by converting sounds into vibration patterns, this in turn helps to people with hearing disability to communicate with others. Another is by converting sound to appropriate pre-loaded images based on the characterization of sound observed, which is very suitable for understanding the conversations through images. By converting these sound signals into vibration patterns and displaying appropriate images related to the sound in the display, this can also notify people about the sound signal propagating around them. This would be very much helpful to the people having hearing disability.

\section{SYSTEM ARCHITECTURE}

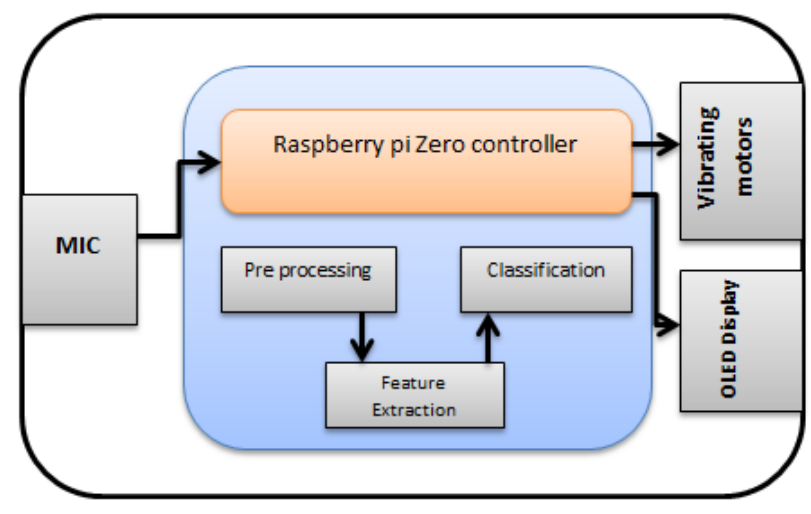

Figure 1.Block diagram of proposed system

\section{A. Block diagram description}

This system includes the high sensitive microphone to sense the sound signal around the device and it can be process by the Raspberry pi zero controller. It does the following image processing techniques like Preprocessing, Feature extraction and classification of the signal by using SVM (support vector machine) technique. Based on the classification of the signal, vibrating motors are actuated appropriately, example (illustrated in Table 1), knocking the door sound can be represented and indicate the deaf in the following manner.

\begin{tabular}{|c|c|c|}
\hline Table 1. Illustration output for Door knock \\
\hline Input & Vibrator & Display \\
\hline Door knock & $\begin{array}{c}\text { Vibrates } 3 \text { times } \\
\text { with } 1 \text { sec delay } \\
\text { between } \\
\text { vibrations }\end{array}$ \\
\hline
\end{tabular}

\section{Published By:}




\section{SYSYTEM DESIGN}

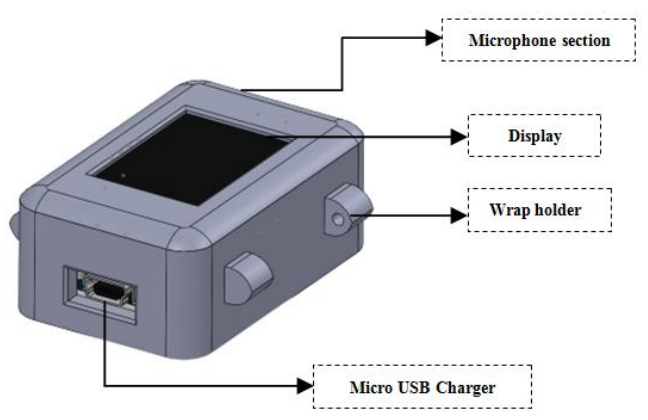

Figure 2.Proposed system design

Our proposed system incorporates two functional units, namely Audio-Visual Conversion and Audio-vibration pattern. Using these systems we ensure that the Conversion, helps the deaf and dumb to understand and react accordingly.

Both systems use artificial intelligence technique to determine specific sounds, like knocking the door, vehicle horns, animal sounds and convert them for hearingimpaired. Audio-Visual Conversion changes sounds into visual warnings that appear in a display associated with the system, whereas Audio-vibration pattern Conversion changes sound into vibrations.

\section{B. Block diagram description}

\section{I2S MEMS Microphone}

I2S microphone sensor is a MEMS type miniature, low power, bottom port microphone with digital output capability. It consists of a high performance sensor to converts an input acoustic signal into digital by an industry standard 24 bits format. I2S interface simplifies the interfacing methodology between the sensor and controller. Thereby it is entirely suitable for portable applications where the size and power consumption is a constraint.

\section{Raspberry pi Zero}

Raspberry Pi Zero is the $1 \mathrm{GHZ}$ single core CPU, is an ideal solution for portable embedded systems. Here it can be incorporated to do the audio processing, including preprocessing of sound signal from the microphone, feature extraction and classification of the signal. Then drive the display and vibrator to perform appropriate action.

\section{Vibrating motor}

In order to intimate the hearing impaired people a device gets vibrate by a very small electric motor with an eccentrically mounted weight on the shaft. When the motor spins, this unbalanced weight makes the device to vibrate with specified pattern.

\section{OLED Displays}

This display is made of $128 \times 64$ individual white OLED pixels interfaced to the controller chip where it can be used to display the pre-loaded image according to the acoustic signal observed. It can be interfaced to controller via SPI or I2C interface.

\section{RESULTS ANDANALYSIS}

Table 2 illustrates results for different input sounds.
Here it represents output for different input sounds like, Door knock, vehicle horn, human being voice, animal sounds and mobile phone ring. For instance a microphone in the device senses the mobile ring sound means, it can be intimated to the hearing impaired people through the preloaded vibration patterns and the images at the output side.

\begin{tabular}{|c|c|c|c|}
\hline S.No & Input sound signal & $\begin{array}{c}\text { Vibrator } \\
\text { output }\end{array}$ & $\begin{array}{c}\text { Visualized } \\
\text { output }\end{array}$ \\
\hline 1. & Door knock & $\begin{array}{l}\text { Vibrates } 3 \\
\text { times with } 1 \\
\text { sec delay } \\
\text { between } \\
\text { vibrations } \\
\end{array}$ & \\
\hline 2. & Vehicle horn & $\begin{array}{l}\text { Vibrates } 2 \\
\text { times with } 1 \\
\text { sec delay } \\
\text { between } \\
\text { vibrations } \\
\end{array}$ & \\
\hline 3. & Human being voice & $\begin{array}{l}\text { Vibrates no. } \\
\text { of times until } \\
\text { he/she can } \\
\text { stop calling }\end{array}$ & \\
\hline 4. & Animal sound & $\begin{array}{c}\text { vibrates } 1 \\
\text { time }\end{array}$ & \\
\hline 5. & Mobile phone ring & $\begin{array}{c}\text { vibrates } 4 \\
\text { times with } \\
0.5 \mathrm{sec} \text { delay } \\
\text { between } \\
\text { vibrations }\end{array}$ & $(() \triangle$ \\
\hline
\end{tabular}

Table 2. Illustrations for Different input sounds

\section{CONCLUSION}

The design and prototype of smart wearable visualizing system for people with hearing impairments has been executed with the appropriate module. The current system is a tiny as well as well portable and wearable for hearing impairment people. The system such a way designed to capture the input sound signal from the environment and converts into appropriate vibrations and visualized output through the vibrating motors and OLED displays.

These kinds of innovation systems definitely assist the disability people in an enormous way and acts as a perfect solution for hearing impaired disability.

\section{REFERENCES}

1. B. B. Leah A. Bushman, and Phyllis Christianson, "Older Adult Hearing Loss and Screening in Primary Care," The Journal for Nurse $\begin{array}{llll}\text { Practitioners, } & \text { vol. } & \text { 8, pp. 509-514, } 2012 .\end{array}$ http://dx.doi.org/10.1016/j.nurpra.2012.03.013

2. P. Mason, "HEARING MADE Clear," in HEARING LOSS RESOURCE GUIDE, ed: American Speech-Language-Hearing Association. 
3. M. P. C. Bevan Yueh, Pamela E. Souza, Patrick J. Heagerty, ChuanFen Liu, Edward J. Boyko, Carl F. Loovis, Stephen A Fausti, and Susan C. Hedrick, "Screening for Auditory Impairment - Which Hearing Assessment Test (SAI-WHAT): RCT design and baseline characteristics," Contemporary Clinical Trials, vol. 28, pp. 303-315, 2007. http://dx.doi.org/10.1016/j.cct.2006.08.008

4. J. G. López-Torres Hidalgo, Clotilde Boix Lapeira, Juan Téllez Verdejo, M Ángeles López del Campo del Campo, José M.Rabadán,and Francisco Escobar, "Functional status of elderly people with hearing loss," Archives of Gerontology and Geriatrics, vol. 49, pp. 2009 . http://dx.doi.org/10.1016/j.archger.2008.05.006

5. J. S. Bamini Gopinath, David Hartley, Erdahl Teber, Catherine M. McMahon, Stephen R. Leeder, and Paul Mitchell, "Incidence and Predictors of Hearing Aid Use and Ownership Among Older Adults With Hearing Loss," Annals of Epidemiology, vol. 21, pp. 497-506, 2011. http://dx.doi.org/10.1016/j.annepidem.2011.03.005

6. D. F. G.-S. Perla B. Becerril-Ramírez, Angélica Gómez-García, Rafael Figueroa-Moreno, Gerardo A. Bravo-Escobar, and Miguel A. García de la Cruz "Hearing Loss Screening Tests for Adults," Acta Otorrinolaringologica (English Edition), vol. 64, pp. 184-190, 2013.

7. S. I. P. Israsena, A. Noymai, S. Boonyanukul, A. Hemakom, C. Chinnarat, N. Navacharoen, and S. Lekagul and 3, "Developing an Appropriate Digital Hearing Aid for Low-Resource Countries: A Case Study," The Scientific World Journal vol. 20132013.

8. L. R. Jean-Baptiste Maj, Jan Wouters, and Marc Moonen, "Comparison of adaptive noise reduction algorithms in dual microphone hearing aids," Speech Communication, vol. 48, pp. 957970, 2006. http://dx.doi.org/10.1016/j.specom.2005.12.005

9. M. O. Hideyuki Takagi, "Interactive Evolutionary Computation Based Hearing Aid Fitting," Evolutionary Computation, IEEE Transactions on, vol. 11, pp. 414-427, 2007. http://dx.doi.org/10.1109/TEVC.2006.883465

10. E. Gyuseok Park, Jeong, Hongsub An, Youngrok, Song, and Sangmin, Lee, "A method to reduce steps and time of hearing test on individual device," in Biomedical Engineering and Informatics (BMEI), 2011 4th International Conference on, 2011, pp. 1955-1958.

11. L.K.Hema et., al"Wearable safety wrist band device for elderly monitoring" Int. J. Chem. Sci.: 14(S3), 2016, 829-834, ISSN 0972$768 X$.

12. V. J. M. A. Pandey, and M. Nilsson, , "Adaptive gain processing to improve feedback cancellation in digital hearing aids," in Acoustics, Speech and Signal Processing, 2008. ICASSP 2008. IEEE International Conference on, 2008, pp. 357-360.

\section{AUTHORS PROFILE}

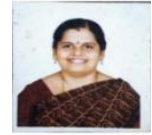

L.K.Hema received her B.E Degree in Electrical and Electronics Engineering from Madurai Kamaraj University, Tamilnadu, in 1990, M.S Degree in Education Management from Alagappa University in the year 2007 and M. Tech Degree in VLSI Design from Sathyabama University in 2009. She has acquired her Doctorate Degree from Manonmaniam Sundaranar University.Since 1991 she has been working as Faculty in the Departments of Computer Science and Engineering, Electronics and Communication Engineering. Her research interests include Wireless Sensor Networks, VLSI Design, Hardware Security and Embedded systems. At present she is working as Professor and Head of the Department at AVIT and engaged in various Government funded projects. She is the life member of ISTE since 2009 and member in IEEE. MAIL ID: hemalk@avit.ac.in, hemjith2005@gmail.com

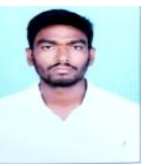

Mr.Velmurugan S, pursued his under graduation degree (B.E) in ECE stream at Aarupadai veedu Institute of technology. Member of IEEE (Institute of Electrical and Electronics Engineers) Society. His Project proposal has been selected as the best by IEEE MADRAS SECTION under SPF scheme for financial support. His area of interest is towards wireless sensor networks. He has carried out lot of projects based on the arduino platform. MAIL ID:vel34.sekar@gmail.com

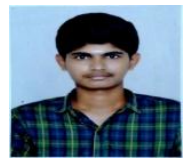

Mr. Mohanraj S, is an UG graduate B.E- in ECE stream at Aarupadai veedu Institute of technology. His area of interest is towards Networking concepts. He has carried out lot of projects based on the arduino platform

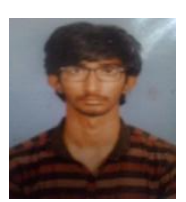

Mr. DhilipKumar T, is an under graduatie in B.EECE stream at Aarupadai veedu Institute of technology. His area of interest is towards VLSI design. He has carried out lot of mini projects based on the arduino platform. 